\title{
BRANDS AND BRANDING - EXAMPLE: COCA-COLA
}

PhD Ljiljana Stošić Mihajlović, Collage of applied professional studies, Vranje, Serbia

\begin{abstract}
The most valuable brand in the world is still "Coca Cola", and the highest increase was recorded value "Apple" because that's who entered the top ten most valuable brands.

Coca-Cola HBC Serbia makes a significant contribution to the local economy. In three bottling plants, distribution centers and sales offices in Serbia and employ over 1500 people. Taxes that are paid regularly Serbian authorities are yet another way of contribution to the national economy.
\end{abstract} Coca-Cola

Keywords: brand, branding, marketing,

\section{INTRODUCTION}

The word brand (trademark) is an English word and its first application was the cowboys of the Old West, which they branded their cows to distinguish them from the other cows on the prairie. From the business point of view on the market, branding is very similar branding at the ranch. The purpose of branding is to differentiate your product in the market from other cows. Even if most of the cattle in the prairie are very similar to each other, the perception of your product must be different.

The rivalry between the world's largest manufacturer of soft drinks, "CocaCola" and "Pepsi" is more than a century.

List as most valuable global brands dominate brand in the U.S., which has a total of 49th From Europe is on the list of 38 brands and from Germany, France, Switzerland, Italy, Britain, Sweden, the Netherlands, Finland and Spain. The other brands are from Japan, Korea, Canada, and one each from Mexico and Taiwan. The research is based on a complex methodology developed by "Interbrend". Use the form that combines the power of brands future and its role in creating demand. Firms must be publicly available financial data, and a third of revenue must come from abroad.
Coca-Cola HBC Serbia is one of the largest companies in the non-alcoholic beverages in the country and authorized bottlers of Coca-Cola. To justify its leadership position in the market, regularly conducts research and a variety of actions in terms of improving their own business and improve the environment.

The most legendary SAGA two brands: Coca-Cola and Pepsi

In fact, it is one of the most iconic stories ever on the fight between the two brands in the business world. Portal CnnTees researched and wrote a chronological tale of two competitors that includes all of the well-known soft drink producers. 'Saga' begins in the 1886th when John S. Pemberton developed the original recipe for the "Coca-Cola". "Pepsi-Cola" appeared 13 years later by pharmacist Caleb Bradhama. At that time, "Coca-Cola" has already sold over a million liters of beverages a year. "CocaCola" soon develops a "cult" and a bottle expands to European market.

Meanwhile, the "Pepsi" is bankrupt because of the First World War, and eight years later, again faced with bankruptcy, but soon coming into her own, and increases sales.

During World War II "Pepsi" is increasing its marketing investment and begin to sell their drinks in cans. During the fifties, "Coca-Cola" is a strong focus on television advertising, and "Pepsi" it is accompanied, not wanting to lose the fight.

1962nd "Coca-Cola" comes to the stock market, and will soon launch a new brand - Sprite - which quickly became one of the world's most successful brands. Connecting to snack producer, the "Frito Lay", "Pepsi" has brought many benefits and helped him considerably, especially in 
the last decade. On the other hand, "CocaCola" has remained in the beverage.

Although "Pepsi" brands of drinks may not be as strong, the job with the production of snack foods, so-called. Nail them literally booming. "Coca-Cola" has a bigger market share drinks, but "Pepsi" because of the wide range of businesses earn higher incomes.

Each of the brands on his side a whole brigade of celebrities, for her marketing job, of course, very well paid. From its founding until the day, and "Coca-Cola", "Pepsi" was implemented numerous changes in the appearance of their logos. Wholeheartedly embraced the popularity of digital media and take advantage of all the marketing advantages of social networks today provide companies.

\section{THE MOST VALUABLE BRANDS}

Brand (after Coca-Cola) are leading the top ten on the list of brands that are just in the United States. From another country is best placed 11th at Toyota place. Coca-Cola is located at the head of the ladder since 2000. when he began to research and to publish. Last year, its value increased by $2 \%$ to 71.861 billion dollars. Second place belongs to IBM, Microsoft and third. From technology companies among the top ten are, and Google, on the fourth, seventh Intel, Apple in eighth and Hewlett-Packard as tenth.

Ladder ten most valuable brands complement the General Electric GE-fifth, McDonald's, Disney, and the sixth to ninth place. Apple's brand value increased by $58 \%$, so the manufacturer of your favorite iPhone and iPad climbed to eighth position from the previous 17th Apple's value has increased mainly due to the dominant position in the market of tablets.

The biggest drop was sustained brand Nokia which has slid to 14th place, with eight, and its value is reduced $15 \%$. Nokia last year was the most valuable
European brand, and now it's Mercedes at the 12th place. Nokia has lately been struggling with problems and had to lay off workers, mainly due to strong competition in the smart phone market.

The new company, which is among the top 100 most valuable brands, the Taiwanese mobile phone manufacturer HTC, which came in 98th place. This is the first time the company found itself on the list of Taiwan.

\section{COCA-COLA HBC SERBIA}

Coca-Cola HBC Serbia is one of the largest companies in the non-alcoholic beverages in the country and authorized bottlers of Coca-Cola. The company manufactures and distributes a unique range of quality brands for around 7.9 million inhabitants of Serbia, bringing enthusiasm in marketing of products, while taking a leadership role in the area of corporate social responsibility.

Coca-Cola HBC Serbia operating in Serbia since 1997. With headquarters in Zemun, has three bottling plants across the country. In addition, distributing products from four distribution centers. It employs over 1,300 people and indirectly affect employment 10 times more people who are in the value chain. Their goal is to provide our customers become the number one supplier to provide and support programs to more than 37,000 customers who sell products to consumers.

This company is part of Coca-Cola Hellenic Group, one of the largest bottler of Coca-Cola in the world and the largest in Europe. Coca-Cola Hellenic operates in 28 countries, offering products for more than 570 million people. You're sitting company located in Athens, and the company is listed on the stock exchange in Athens, New York, London and Sydney.

\subsection{The product range}

Coca-Cola HBC Serbia produces, sells and distributes a wide range of 
beverages, most of which are the trademark of Coca-Cola. Our product portfolio includes:

- Leading brands: Coca-Cola, Coca-Cola light, Coca-Cola, Fanta and Sprite

- Local brands such as Rosa, Next, SU-Fruit, Joy

- Brands licensed from other companies, such as Nestea, Burn, Ultra Energy and Schweppes.

Continuously consider opportunities to expand its product range in order to offer consumers the ability to Serbia as diverse choices. We do our best to provide the highest quality of its products.

\subsection{Sustainable Development}

To ensure long-term success, CocaCola HBC Serbia impact on the environment to a minimum and contributing to the quality of life in local communities. Long term and are committed to constantly meeting these goals. Given the growing number of sustainability challenges, focus on issues that are a priority for the business. These are:

- Management of water resources

- Climate protection \& protection of energy resources

- Packaging \& Recycling

- Consumer Health

- Developing people

- Engaging suppliers community

- The well-being of the local

- United Nations Global Compact

For each of these issues are set objectives, monitoring and measuring the progress equally rigorous as in other segments of its business. Follow the leading standards and methodologies and operations transparent reporting on the progress made in the report on corporate social responsibility (CSR).

\subsubsection{Management of water resources}

The needs for fresh water in our environment are increasing, and climate change affect traditional forms of precipitation. As the number of inhabitants in the country, the needs for drinking water are becoming alarming.

Capacity Business Development, Coca-Cola HBC Serbia is directly related to the availability and quality of local water resources. Therefore the greatest efforts are directed towards managing water resources and taking an integrated approach to this issue, which is of key importance:

First Improving water use efficiency: it is to reduce the amount of water needed for the production of beverages

Second Working in partnership in order to protect local rivers and promote sustainable management of water resources, works with partners whose number is getting bigger

The bottlers are closely monitoring water resources in order to amount of water pumped to a minimum. Introducing water-saving technology on the production lines, made more efficient use of water. For example, to install a washing systems which operate on the principle of high pressure, significantly reduce the consumption of water, water that is used for the five lines washer is collected and used for the toilets; syrups is made in the program in which the last flush with water sanitation collected and used as the starting point for the next sanitation, for Water treatment devices are installed that measure water consumption for each product line, which significantly improved monitoring of water consumption in the production.

Each bottling plant regularly to assess risk. Regularly to study and monitor the quantity and quality of local water supplies taking into account the legal requirements and the environment. Based on the assessment made in order to create an action plan to mitigate the risks. 
Although they managed to increase water use efficiency to a great extent, will never be able to influence the reduction of the amount of water in the products. What is being produced greater amounts of alcohol, it will use more water. Therefore, it is extremely important to continue to work on the efficient use of water. This is exactly the reason I constantly investing in new, more modern technology.

Coca-Cola HBC Serbia provides all the water that is returned to the Danube, is processed to a level that allows the fish to live in it. The bottling plant in Serbia have waste water treatment plants located on the factory grounds, and Vlasinka and Fresh \& Co using public utility systems for water treatment. Treated water is returned to the environment is suitable for use in agriculture and safe for plants and aquatic life.

\subsubsection{Partnerships}

In order to successfully cope with problems related to water resources, CocaCola HBC Serbia is cooperating with other stakeholders through a series of partnerships.

Green Danube Partnership for there for many years. Together with the International Commission for the Protection of the Danube River, to participate actively in the struggle to preserve the river and conduct a variety of activities aimed at raising awareness both in Serbia and in nine other countries that lie in the basin of this river. These activities include the annual Danube Day celebrations in which take part in the tens / hundreds of thousands of people. Celebration organized by Coca-Cola HBC Serbia, in partnership with the Ministry of Agriculture, Forestry and Water Management - Republic Directorate for Water, the City of Belgrade, Secretariat of Environment of Belgrade, Recycling Agency of Republic of Serbia, Secretariat for Utilities and Housing for the city of Belgrade, Tourist Organization of
Belgrade, Faculty of Applied Ecology, University of Belgrade, NGO world and the Danube and many other associations, representatives of ministries and relevant media partners. It also sponsors the first conference on groundwater, and began a project to protect the river Vlasina.

At the international level, the CocaCola Hellenic is a signatory of the CEO Water Mandate the establishment of the UN Global Compact. This initiative aims to tackle the problem of sustainability of water resources in operations, supply systems and communities as well as to work closely with government and nongovernmental organizations involved in shaping policy in this area. In order to achieve a better understanding of water use in the domestic supply system, Coca-Cola is also working with Water Footprint Network.

\subsubsection{Energy Efficiency}

Climate change is the biggest and most alarming challenge facing our planet. It takes quick and decisive action to ensure that our society is focused on the development path that will feature a low carbon economy. The business sector, which has a capacity for innovation and investment, plays a key role in the transformation of large-scale.

Coca-Cola HBC Serbia wants to take a leadership position so that there will be adapting their business demands and opportunities of the economy characterized by low carbon emissions. Therefore, all efforts directed towards the areas of operations that derive the greatest amount of energy: bottling plant, vehicles and refrigeration equipment.

- The Coca-Cola bottling plant Serbian expanding the program Safe and Eco-Driving

- The transportation services beyond the use of hybrid vehicles and alternative fuels. Also, through the "Safe and Eco-driving" influence creation of good habits in the run. 
- Coca-Cola HBC Serbia has a new energy-efficient refrigeration equipment that emits $50 \%$ less $\mathrm{CO} 2$ compared to the results from 2004.

- Combined heat and power: The largest reduction in carbon dioxide from the bottling plant will just come from plants that combine electricity and heat (CHP), and for developing plans and receive approval on CHP approval of construction in Serbia and elsewhere in the Group. Cleaner and much more efficient than conventional power plants, the combined units located within the plant bottling supplier of electricity, heating and cooling. When you finish, the program will lead to a reduction in $\mathrm{CO} 2$ emissions originate from all manufacturing plants to $20 \%$, while Coca-Cola HBC Serbia and up to $40 \%$.

- energy-saving programs: The Coca-Cola HBC Serbia during bottling is the application of energy-saving, which will lead to a reduction in $\mathrm{CO} 2$ emissions per liter of beverage produced. It is interesting that even though their production facilities use more energy than office space and other applications, certain measures are taken in terms of reducing $\mathrm{CO} 2$ emissions in those areas. For example, the Green IT program works to change the computer equipment used in creating good user habits. Using audio, video and on-line conferencing, reducing business travel and hence $\mathrm{CO} 2$ emissions.

- Energy efficient refrigerator: When thirsty, consumers expect in restaurants and stores find products, chilled and ready for consumption. Because of this, an important part of the business strategy of Coca-Cola HBC Serbia involves setting up cooling systems and equipment in buildings buyers. Although not produce themselves, and they do not operate this equipment, they are liable to affect the reduction of $\mathrm{CO} 2$ emissions resulting from these devices. Therefore, working with suppliers to increase the energy efficiency of the equipment used. Thanks to the development of new models of refrigeration equipment and devices to control energy use, the equipment is purchased now, in terms of energy consumption, $50 \%$ more efficient than the one in 2004. year. We are also conducting training programs for its employees to ensure proper use of these devices on the market.

In addition, working to avoid hydro-fluor-carbonate (HFC) compounds, greenhouse gases, which are widely used in refrigeration equipment in homes and businesses.

\subsection{Partnerships}

At the international level, the CocaCola Hellenic is one of the founders and a signatory of the UN Global Compact on Climate Protection, the world's largest business association centered around issues of climate protection. In Serbia, an active member of UNGS and early 2009. was selected as the chair of the group for the environment in which it will focus this year will be very energy efficient.

\subsection{Packaging and recycling}

Packaging plays a vital role in the safe delivery of products to customers and consumers. However, once the product takes, it becomes a quality packaging material for recycling, leaving the burning furnaces that produce waste heat energy or ends up as landfill waste.

We strive to reduce our impact on the environment which originates from the packaging in any part of its life cycle. Our integrated approach includes:

- Reducing the amount of packaging we use

- Increase recycled content in the composition of new packaging

renewability

- Promote recycling and

The ultimate goal is to close the circle of recycling, conversion of used packaging in the new one. Bottle-to-bottle 
recycling plant whose establishment in Austria just helped Coca-Cola Hellenic, the company now supplies high quality and very affordable recycled material from which to make new bottles. In addition to working on to reducing packaging waste to a minimum and also try to reduce our waste production and bottling.

Reducing the amount of packaging we use to a minimum, which is one of the most important ways in which generally reduce the impact on the environment by reducing the amount of material used for packaging, this also leads to an overall reduction in $\mathrm{CO} 2$ emissions generated during the life cycle of packaging of production through transportation to disposal or recycling. Rosa Danube PET bottles is one of the lightest on the market. Weighing just 15 grams and is nearly three times lighter than the one that preceded it. Ultra-glass bottle which is used to produce one-third less glass, is now in use in Serbia and 16 other countries in which Coca-Cola Hellenic conduct business.

Packaging consists primarily of recycled material: PET, aluminum, glass and steel. Since these are the most common materials recycled, the only thing that can be done to reduce the impact of our packaging on the environment is that in these materials is steadily increasing content of recycled materials. Using recycled aluminum for cans, saving up to $95 \%$ of the energy normally required when using non-recycled aluminum. Our aluminum cans and glass bottles already contain up to $60 \%$ recycled material. Turning recycled PET bottles in our challenge in terms of availability and cost. Although the recycling of PET widespread (in Serbia is much cheaper and easier to use the same in the production of other goods, such as clothing or carpets, as well as the industry itself does not require such high standards necessary when it comes to packaging for food products) .

In the seven countries where the company operates and to use $15 \%$ recycled PET material.

\subsubsection{Promoting recycling}

Coca-Cola HBC Serbia strongly helps establish the necessary infrastructure for recycling and encourages consumers to recycle packaging. We are working on establishing a scheme of packaging waste management in Serbia, as they have done in other countries in which Coca-Cola Hellenic operates. They are one of the founders of Sekopak organization that advocates for the adoption of the legal framework in the field of packaging and packaging waste on the model and in accordance with the regulations that exist in the EU Directive 94/62/EC on packaging and packaging waste posed Agreement to utilization and recycling before all entities in the chain to the end user - the producers, packers / fillers, importers, distributors and retailers, putting them in position to make reuse of packaging placed on the market by the percentage that the State may determine. This principle of "responsibility of waste generators" is incorporated into the Serbian Law on Waste Management and the Law on Packaging and Packaging Waste, adopted in May 2009. by the Parliament of Serbia. So far, the company has helped establish the system in 19 countries and is the co-owner of 17 companies involved in recycling and waste recovery.

\subsection{Staff development}

Business objectives can be achieved only with the help of talented and committed people. Therefore we strive to attract skilled people and develop their full potential.

\subsubsection{Training and Development}

One way in which this is achieved Coca-Cola HBC Serbia lies in providing exceptional opportunities to build a career. They invest heavily in formal training, which combined with other tasks and 
projects of equal development opportunities. This structured approach allows you to develop leadership skills necessary for the successful conduct of the business now and in the future.

\subsubsection{Employee Engagement}

To ensure motivation and commitment of employees at Coca-Cola HBC Serbia regularly make information of employees and listen carefully to their views. This is done in various ways, through: internal magazine, suggestion boxes, bulletin boards, internal TV and other means of communication with employees. On an annual basis conduct research on engagement, which allows employees to express their views on a range of topics? Then carefully examine the data and based on their suggestions and make action plans.

\subsubsection{Competitive labor}

Salaries of employees of CocaCola HBC Serbia are getting competitive in the market. In order to comply with the competition, comparing regular compensation received by employees in return for other successful companies.

\subsubsection{Fair working environment}

Coca-Cola HBC Serbia respects the fundamental rights of employees and strives to create an open and positive working environment that provides equal opportunities to all. Policies are well known and are an integral part of the training program manager. Also, the guiding principles for suppliers ask the same expectations and vendor environments.

\subsubsection{Human rights}

Coca-Cola HBC Serbia Politics of Human Rights includes monitoring provisions of the UN Global Compact and the UN Universal Declaration of Human Rights. Employment of children is prohibited, and accordingly shall be permanent and checks during the hiring process. Employees and managers are trained regarding the use of human rights in their daily operations, and regularly performs and monitoring actual performance.

\subsubsection{Equal Opportunity}

Dedicated to creating an environment in which all employees to act in a fair and equitable manner. Equal opportunities policy protects employees from discrimination and ensuring that there is equal opportunity and fair treatment for all. Although men predominate among employees, in part because of the physical nature of the work, a significant number of our managers are women - $25 \%$ of total management. Almost all the managers of Coca-Cola HBC Serbia at higher positions are from Serbia. Where are temporarily appointed managers from foreign countries, local talented employees are sent on assignments abroad to acquire new skills.

\subsubsection{Relationship with employees}

The Coca-Cola HBC Serbia respects the right of employees to freedom of association: whether or not to join unions or engage in collective bargaining. Regularly holds consultations employees, unions, and office of the European Council for labor in terms of major business decisions and matters of common interest.

\subsubsection{Health and Safety}

The aim of Coca-Cola HBC Serbia is to provide its employees a safe working environment and in this respect a culture of safety at work. To achieve this, apply the internationally recognized OHSAS 18001 management systems and strives to achieve full certification. 
Implemented a program to promote healthy and active lifestyles of employees.

- Each year, they organize "Sports Day" for its employees and their family members.

- provide support to employees who are engaged in recreational sports, and bear part of the cost of membership in a number of centers of fitness.

- A healthy lifestyle is knowledgeable and management through the "Fit for the Future" organized by the Academy of Coca-Cola Company.

\subsection{Creating economic value}

Coca-Cola HBC Serbia makes a significant contribution to the local economy. In three bottling plants, distribution centers and sales offices in Serbia and employ over 1500 people. Taxes that are paid regularly Serbian authorities are yet another way of contribution to the national economy.

In addition, they provide a range of other, indirect benefits. For example, the "multiplier effect" that business has seen in the fact that for every job that exists in this system goes ten times as many jobs provided by vendors and buyers. Given the fact that one of the main investors in Serbia, helping introduction and development of new technologies and thereby influence the attraction of new investments.

\section{CONCLUSION}

Old rule is that a company that cares about its products, constantly examining and verifying their market position, contributing to the creation of brand products.

It is believed that the most important function of marketing today just building a brand. What's more, many of the world's leading marketing experts believe that the main function of marketing and only building a brand. What is accelerating this trend is steadily declining sales of classic vision and the ways to be exchanged goods and money in the market. Today, most products on the market are not sold are purchased. Consumers themselves are directly confronted with the products (brands), and the decision to buy is up to them. Bearing the aforementioned in mind, Coca-Cola HBC Serbia is a leader in the market of non-alcoholic beverages.

\section{Reference}

1. Stošić Mihajlović, dr Lj. (2012) Marketing, VŠPSS, Vranje

2. Stošić Mihajlović, dr Lj. (2011) Istraživanje marketinga, VŠPSS, Vranje

3. www.coca-

colahellenic.rs/Productsandbrands 